\title{
La Atención Temprana en contextos penitenciarios en España
}

\section{Early Intervention in prisons in Spain}

\author{
Leticia López-Castro, María José Buceta-Cancela \\ *Grupo de Investigación ESCULCA-Rede RIES. Universidade de Santiago de Compostela
}

\begin{abstract}
Resumen
En España, los hijos de las reclusas pueden residir junto a ellas en centros penitenciarios hasta que alcanzan el tercer año de vida. Esta convivencia garantiza un vínculo afectivo entre el infante y la progenitora pero también sitúa a los niños en un contexto reconocido como factor ambiental de riesgo para su desarrollo. De ahí que nuestro principal objetivo se traduzca en determinar si la Atención Temprana permitiría dar respuesta a sus necesidades psicosocioeducativas. Tras un exhaustivo análisis documental y la explotación de datos secundarios, los resultados indican que resulta imprescindible la Atención Temprana para abordar dichas necesidades.

Palabras clave: desarrollo infantil, tratamiento penitenciario, atención temprana.
\end{abstract}

\begin{abstract}
In Spain, the children of women prisoners may reside with them in prison until they turn three years old. This coexistence ensures a bond between the child and his mother but at the same time places children in a context recognized as an environmental risk factor for their development. Hence, our main objective is to determine whether the early intervention will meet their psychological, social and educational needs. After an exhaustive document analysis and secondary data exploitation, the results indicate that early intervention is essential to address these needs.
\end{abstract}

Keywords: child development, correctional institutions, early intervention.

\section{Introducción}

Los hijos e hijas de las reclusas que residen en centros penitenciarios en España constituyen nuestro objeto de investigación. Son escasas las investigaciones que se han llevado a cabo en torno al mismo pero diversos autores afirman la necesidad de ampliar el conocimiento en este ámbito (Jiménez y Palacios, 1998; Weissgerber y Delens-Ravier, 2007; Ruiz Soriano, 2014). Su importancia se entrelaza con el compromiso de garantizar los derechos de la infancia, en concreto, aquellos establecidos por la Convención sobre los Derechos del Niño (1989) que determinan que el Estado garantizará, en la máxima medida posible, la supervivencia y el desarrollo de los infantes (art. 6) ya que reconoce el derecho de todo niño a un nivel de vida adecuado para su desarrollo físico, mental, espiritual, moral y social (art. 27). En consecuencia, debemos prestar especial atención a la infancia que reside en centros penitenciarios ya que las condiciones en las que se encuentran suponen un riesgo para su desarrollo.

Es por ello que nuestros principales objetivos son determinar si la Atención Temprana permitiría dar respuesta a las específicas necesidades psicosocioeducativas de los hijos de las reclusas así como estudiar las posibilidades que la Atención Temprana puede ofrecer en este contexto.

\section{Método}

Con el fin de alcanzar los objetivos propuestos, hemos llevado a cabo un exhaustivo análisis documental y la explotación de datos secundarios.

Para la recogida de la información se ha empleado la técnica bibliográfica. Cabe mencionar que, en España, destacan obras recientes como la de Yagüe Olmos (2006) que aborda la situación de las madres en prisión, aportando una visión histórica sobre las cárceles de mujeres a través de su vertiente maternal. Asimismo, el trabajo de Naredo (2007) comparte dicha temática pero se centra en el análisis de la legalidad de las reclusas que conviven con sus descendientes en la cárcel. Y por último, Jiménez y Palacios (1998) realizaron una investigación centrada en el desarrollo psicosociobiológico de las niñas y niños residentes en centros penitenciarios. No obstante, es preciso indicar que se trata de un escaso número de investigaciones y además, la información disponible sobre las necesidades psicosocioeducativas de los infantes que se encuentran en dicha situación es parcial y poco concluyente.

Con respecto al tratamiento de la información, hemos optado principalmente por la técnica de fichaje lo que nos ha permitido disponer de un depósito organizado de los datos del trabajo. En concreto, hemos desarrollado dos clases de fichas: bibliográficas y de trabajo.

\section{Resultados}

El exhaustivo análisis documental y la explotación de datos secundarios nos han permitido estudiar las posibilidades que la Atención Temprana puede ofrecer en este contexto.

Los resultados evidencian que hemos avanzado en la atención a la infancia en centros penitenciarios buscando dispositivos más flexibles, como las Unidades de Madres, y procurando que los niños desarrollen parte de sus actividades en un ambiente comunitario normalizado. No obstante, Jiménez y Palacios (1998) afirman que las condiciones del entorno donde viven los niños presentan 
especial trascendencia para su ulterior desarrollo y socialización. Asimismo, destacan que una de estas condiciones especialmente crítica es la de "los niños en situación de vulnerabilidad al ser tributarios muy tempranamente de los especiales riesgos derivados del encarcelamiento” (Jiménez y Palacios, 1998, p.11).

De tal modo, estos centros por sus propias características como son su restrictivo régimen, los limitados espacios y las escasas oportunidades de interacción pueden comprometer su desarrollo integral e incluso, podrían facilitar la aparición de dificultades en la adquisición de determinados hitos de su desarrollo. De ahí que el nacimiento y/o la permanencia en prisión se reconozcan como un factor ambiental de riesgo para el desarrollo infantil de acuerdo a la Organización Diagnóstica para la Atención Temprana (2008).

Ante esta situación de riesgo para el desarrollo infantil, las posibilidades de la Atención Temprana la convierten en una medida inexcusable en contextos penitenciarios. Así, la Atención Temprana consiste en un conjunto de acciones orientadas hacia la prevención y la intervención asistencial de los niños y niñas que se encuentran en situación de riesgo $y$, a su vez, un conjunto de intervenciones con el que se actúa para poder garantizar las condiciones y la respuesta familiar ante estas circunstancias. De este modo, "no puede ser vista exclusivamente como una vertiente de la rehabilitación" sino que permitiría tanto la prevención de trastornos del desarrollo como la intervención temprana y la intervención familiar (Federación Estatal de Asociaciones de Profesionales de Atención Temprana, 2005, p.10).

Por tanto, la Atención Temprana en centros penitenciarios posibilitaría, por una parte, la detección temprana de los trastornos del desarrollo infantil lo que constituye el paso imprescindible para el diagnóstico y la intervención. La detección temprana es ineludible para poder incidir en una etapa del desarrollo que destaca por la gran plasticidad del sistema nervioso lo que permite que las posibilidades terapéuticas alcancen su mayor eficacia. Por otra parte, la Atención Temprana en centros penitenciarios nos permitiría prestar especial atención a las madres ya que constituyen la principal fuente de estimulación infantil. Ruiz Soriano (2014, p.197) ya ha puesto de manifiesto la necesidad de formación de las madres que "no están acostumbradas a jugar con ellos, a correr con ellos y a estar detrás, entonces tenemos que enseñarles”. En esta línea, Jiménez y Palacios (1998, p.280) destacan la necesidad de "mejorar el conocimiento que las madres tienen de los niños, de su desarrollo y de sus necesidades, con el objetivo de mejorar la calidad de la estimulación que reciben”. Por lo tanto, es preciso potenciar las capacidades parentales para garantizar diversas y positivas oportunidades de estimulación infantil.

Para ello, se podrían llevar a cabo un conjunto de actividades de aprendizaje dirigidas a las madres con el objetivo de proveerlas de modelos adecuados de prácticas educativas. La intervención con las familias como parte de la Atención Temprana en centros penitenciarios se sustenta en el hecho de que los padres que participan en programas de formación aumentan la estimulación hacia sus hijos y mejoran la calidad de sus interacciones, además se observa un efecto positivo en el desarrollo infantil cuando se realiza a una edad temprana (Vila Mendiburu, 2000).

En definitiva, podemos concluir que la Atención Temprana basada en la prevención e intervención asistencial de estos infantes, desde el inicio de su permanencia en dichos dispositivos penitenciarios, así como en la intervención familiar resulta imprescindible porque contribuiría a responder a las complejas necesidades psicosocioeducativas del niño que se pueden ver afectadas por el contexto en el que vive.

\section{Discusión}

Cuando se opta por la permanencia de los niños en los centros penitenciarios se produce una situación que confronta derechos y principios jurídicos de primera magnitud tales como los establecidos en la Convención sobre los Derechos del Niño de 1989.

Esta situación ha dado lugar a un intenso debate científico, siempre inconcluso, y a la paulatina adopción, por parte de la administración penitenciaria, de medidas más acordes con la infancia.

En España, la Ley 13/1995 que modifica la Ley Orgánica General Penitenciaria de 1979, redujo el límite de edad de permanencia de los infantes en prisión de los seis a los tres años de vida. Esta modificación se ha justificado en base a que la convivencia de los menores hasta la edad de seis años, podía llegar a comportar graves disfuncionalidades en su desarrollo emocional y psicológico, dado que serían conscientes de la privación de libertad que afecta a sus madres y vincularían la conformación de su personalidad inicial a tal hecho.

El Real Decreto 190/1996 por el que se aprueba el Reglamento Penitenciario de desarrollo y ejecución de la Ley Orgánica General Penitenciaria de 1979, explicita las formas especiales de ejecución de la pena para las madres, es decir, los dispositivos penitenciarios tales como Unidades Dependientes, Unidades de Madres, Unidades Externas de Madres y Módulos Familiares. Estas medidas han sido desarrolladas por el sistema penitenciario español para prestar atención específica a la infancia y prevenir la desestructuración de los grupos familiares que tengan varios miembros en prisión.

Es por ello que podemos considerar que nuestro sistema penitenciario ha ido avanzando hacia medidas y dispositivos más normalizados con la intención de posibilitar un correcto desarrollo integral de los niños y niñas que residen en este contexto. No obstante, las características de los centros penitenciarios son un factor ambiental de riesgo para el desarrollo infantil lo que nos sitúa sobre la necesidad de la atención temprana para garantizar, tal como hemos indicado, la prevención e intervención así como una respuesta familiar a las necesidades psicosocioeducativas de los menores.

Por el contrario, se podría optar por alternativas a la condena a prisión de las madres mediante procedimientos que no comporten el ingreso en un medio cerrado o bien introducir regímenes de semi-libertad, ya que tal como indican Weissgerber y Delens-Ravier (2007, p.6) “únicamente así sería posible resolver este 
problema y evitar daños indirectos que a la sociedad y al individuo provocan las penas de prisión”.

En definitiva, este trabajo nos lleva a plantearnos diversos interrogantes sobre las necesidades psicosocioeducativas concretas de estos niños, las características de su desarrollo tras la salida de los centros penitenciarios, etc. Para dar respuesta a estas y otras cuestiones, será preciso continuar esta línea de investigación, aproximándonos a la situación actual de los infantes en instituciones penitenciarias.

\section{Referencias}

Federación Estatal de Asociaciones de Profesionales de Atención Temprana (2005). Libro Blanco de la Atención Temprana. Madrid: Real Patronato sobre Discapacidad.

Jiménez, J. y Palacios, J. (Coords.) (1998). Niños y madres en prisión. Desarrollo psicosociobiológico de los niños residentes en centros penitenciarios. Madrid: Organismo Autónomo de Trabajo y Prestaciones Penitenciarias.

Naredo, M. (2007). Reclusas con hijos/as en la cárcel. En E. Almeda, y E. Bodelón (Eds.), Mujeres y Castigo: Un enfoque socio-jurídico y de género (pp. 263-277). Madrid: Editorial Dykinson.

Organización Diagnóstica para la Atención Temprana (2008). Manual descriptivo ODAT: Actualización 2008. Madrid: Real Patronato sobre Discapacidad.

Ruiz Soriano, M. A. (2014). Situación de la mujer y sus hijos en los centros penitenciarios. Unidad Externa de Madres Padre Jaime Garralda. En F. J. del Pozo Serrano y C. Peláez Paz (Coords.), Educación Social en situaciones de riesgo y conflicto en Iberoamérica (pp. 192-200). Madrid: Universidad Complutense de Madrid.

Vila Mendiburu, I. (2000). Intervención psicopedagógica en el contexto familiar. En M. J. Rodrigo y J. Palacios (Coords.), Familia y desarrollo humano (pp. 501-519). Madrid: Alianza Editorial.

Weissgerber, G. y Delens-Ravier, I. (Coords.) (2007). La infancia con el padre o la madre en prisión. Barcelona: Hacer.

Yagüe Olmos, C. (2006). Madres en prisión: Historia de las Cárceles de Mujeres a través de su vertiente maternal. Granada: Editorial Comares.

\section{Agradecimientos}

A la Dra. María del Mar Lorenzo Moledo por su destacada colaboración para el desarrollo de la investigación. 